ERRATUM

\title{
Effects of active psychosocial stimulation on social interactions of people with dementia living in a nursing home: a comparative study - ERRATUM
}

\author{
Jean-Bernard Mabire, Marie-Claire Gay, Pierre Vrignaud, Catherine Garitte, \\ Yun-Hee Jeon and Myrra Vernooij-Dassen
}

DOI: https://doi.org/10.1017/S1041610217002046, Published by Cambridge University Press, 10 October 2017

The above article was published with the incorrect title.

The correct title should read "Effects of active psychosocial stimulation on social interactions of people with dementia living in a nursing home: a comparative study".

The editor and publisher regret this error.

The original article has been corrected online to rectify this error.

\section{Reference}

Mabire, J.-B., Gay, M.-C., Vrignaud, P., Garitte, C., Jeon, Y.-H. and Vernooij-Dassen, M. (2017). Effects of active psychosocial stimulation on social interactions of people with dementia living in a nursing home: a comparative study. International Psychogeriatrics, 30. doi:10.1017/S1041610217002046. 